\title{
Dendroarchitecture and Lateral Inhibition in Thalamic Barreloids
}

\author{
Philippe Lavallée and Martin Deschênes \\ Centre de Recherche Université Laval-Robert Giffard, Hôpital Robert-Giffard, Québec G1J 2G3, Canada
}

\begin{abstract}
Thalamic cells that relay vibrissa information to barrel cortex are clustered within whisker-related modules termed barreloids. Each barreloid receives input from one principal whisker and inhibitory inputs from reticular thalamic neurons with receptive fields that correspond to that same whisker. Although the proximal dendrites of relay cells are confined to their home barreloid, distal dendrites often extend into surrounding barreloids representing adjacent whiskers on the mystacial pad. It was proposed that this arrangement provides a substrate for a mechanism of lateral inhibition that operates remotely on extrabarreloid dendrites. In the present study, we identified adjacent whiskers that suppressed activity below background levels in barreloid cells, and we used a double-labeling protocol to relate the efficacy of inhibition to the dendroarchitecture of the cells. Significant suppression of background discharges was produced by $92 \%$ of adjacent whiskers within rows, by $48 \%$ of adjacent whiskers within arcs, but was never observed after deflection of nonadjacent whiskers. The magnitude of lateral inhibition increases linearly as the cumulated length of dendrites increases in the barreloid representing an adjacent whisker $\left(R^{2}=0.86 ; p<0.0001\right)$. As distance between cell bodies and the border of an adjacent barreloid increases, dendritic length in that adjacent barreloid diminishes and so does inhibition. Considering time differences between the arrival of principal and adjacent whisker inputs in barreloids, our data suggest that inhibition operating distally on dendrites acts as a spatial filter that primarily suppresses adjacent whisker inputs and so contributes to enhance edge detection.
\end{abstract}

Key words: barrels; whisker; vibrissa; ventral posterior medial nucleus; thalamic relay cells; reticular thalamic nucleus

\section{Introduction}

Studies of the lateral eye of the horseshoe crab Limulus polyphemus have provided us with the concept of lateral inhibition as a mechanism of edge enhancement (Hartline, 1942). This concept was later extended to the vertebrate retina and integrated into the notion of receptive field with antagonistic center-surround organization (Kuffler, 1953). Since then, lateral inhibition revealed itself as a ubiquitous mechanism that operates at all levels in sensory systems (von Bekesy, 1967; Yokoi et al., 1995; Pollak et al., 2002).

In the vibrissal system of rodents, lateral inhibition is often referred to as adjacent whisker-evoked or cross-whisker inhibition. It has been found at each of the relay stations in this system, but circuits that mediate lateral inhibition in brainstem and cortex remain poorly understood (Simons and Carvell, 1989; Welker et al., 1993; Brumberg et al., 1996; Ghazanfar and Nicolelis, 1997; Goldreich et al., 1998; Brecht and Sakmann, 2002; Bruno and Simons, 2002; Minnery and Simons, 2003; Minnery et al., 2003). Only in the ventral posterior medial nucleus (VPM) of the thalamus do we know which neurons are involved and their connections. The VPM of rodents contains a single class of neurons, the

Received March 16, 2004; revised May 3, 2004; accepted May 19, 2004.

This work was supported by Canadian Institutes for Health Research Grant MT-5877 to M.D. and a Fonds de la recherche en santé du Québec doctoral fellowship to P.L.

Correspondence should be addressed to Dr. Martin Deschênes, Centre de Recherche Université Laval-Robert Giffard, 2601 de la Canardière, Québec City, Canada G1J 2G3. E-mail: martin.deschenes@crulrg.ulaval.ca. D01:10.1523/JNEUROSCI.0973-04.2004

Copyright $\odot 2004$ Society for Neuroscience $\quad$ 0270-6474/04/246098-08\$15.00/0 relay cells (Barbaresi et al., 1986; Harris, 1986; Ohara and Havton, 1994), which are clustered within whisker-related aggregates termed barreloids. Each barreloid contains neurons that respond strongly to the motion of one vibrissa, the principal whisker (PW), and more weakly to that of one to four adjacent whiskers (AWs) (Simons and Carvell, 1989; Armstrong-James and Callahan, 1991; Chiaia et al., 1991; Diamond et al., 1992; Friedberg et al., 1999; Minnery et al., 2003). Axons of relay cells do not branch locally in VPM but give off collaterals in the nucleus reticularis thalami (nRT) as they move toward barrel cortex (Harris, 1987; Pinault and Deschênes, 1998). Reticularis cells are GABAergic and return inhibitory projections to the barreloids.

In a previous study, we reported that a thalamic barreloid representing a given whisker receives inhibitory inputs from nRT neurons with receptive fields that correspond to that same whisker (Désîlets-Roy et al., 2002). Within a barreloid, nRT axons synapse onto the cell bodies and dendrites of residing neurons as well as onto the distal dendrites of neurons with cell bodies that are located in adjacent barreloids (Varga et al., 2002). It was proposed that this arrangement provides a substrate for a mechanism of lateral inhibition that operates remotely on distal dendrites, and that the spread of dendritic trees among surrounding barreloids determines spatial patterns of AW-evoked inhibition.

In the present study, we tested this proposal in a preparation in which VPM and nRT cells were rendered monowhisker responsive by lesion of the interpolaris division of the brainstem trigeminal complex (SpVi) (Lee et al., 1994a; Friedberg et al., 1999; Timofeeva et al., 2004). The topography of lateral inhibi- 
tion was assessed quantitatively by controlled deflection of AWs, and a double-labeling protocol was used to ascertain that the presence and efficacy of inhibition relate to the spread of dendrites in surrounding barreloids.

\section{Materials and Methods}

Animal preparation. Experiments were performed in 33 male rats (Sprague Dawley, 250-300 gm) in accordance with federally prescribed animal care and use guidelines. Rats were initially anesthetized with pentobarbital $(50 \mathrm{mg} / \mathrm{kg})$, supplemented as needed by a small amount of xylazine $(1 \mathrm{mg} / \mathrm{kg})$. The left facial nerve was cut, and the rat was placed in a stereotaxic apparatus. Throughout the experiment, the animal breathed freely, and body temperature was maintained at $37.5^{\circ} \mathrm{C}$ with a thermostatically controlled heating pad. A unilateral electrolytic lesion of the SpVi was made with a tungsten electrode (tip diameter, $\sim 200 \mu \mathrm{m}$; deinsulated over $500 \mu \mathrm{m}$ ). The electrode was lowered through the cerebellum ( $12 \mathrm{~mm}$ behind the bregma, $3.2 \mathrm{~mm}$ lateral to the midline) (Paxinos and Watson, 1986) until the floor of the brainstem was reached. Then the electrode was retracted in steps of $500 \mu \mathrm{m}$, and DC (3 mA, $4 \mathrm{sec})$ was applied at four depths.

Two stainless steel tubes (diameter, $1.5 \mathrm{~mm}$; length, $15 \mathrm{~mm}$; spacing, $10 \mathrm{~mm}$ ) were fixed across the surface of the skull by means of screws and acrylic cement. For the recording session, the rat's head was maintained in a stereotaxic position by means of a small $\mathrm{U}$-shaped frame bearing adjustable pins inserted in the tube openings of the cemented device. The frame was secured to a large steel post so that whiskers on the left mystacial pad were freely accessible for stimulation. Before the start of recordings, the nape of the neck was infiltrated with long-lasting local anesthetics (Marcaine 1\%) to reduce animal discomfort. Local anesthesia produced a remarkably still preparation in which the electroencephalogram (recorded in two rats) displayed spindles and a dominance of 5-7 $\mathrm{Hz}$ activity. Animals remained motionless with occasional twitches of the right whiskers, indicating that they did not experience any discomfort, but they briskly reacted to a moderate pinch of the hindlimbs. Together, these signs are indicative of a light anesthesia stage (stage III-2) (Friedberg et al., 1999). An additional dose of anesthetics (ketamine, $20 \mathrm{mg} / \mathrm{kg}$ ) was given when small amplitude-whisking movements were noticed.

At the end of the recording sessions, animals were perfused under deep anesthesia with saline followed by a solution of $4 \%$ paraformaldehyde and $0.5 \%$ glutaraldehyde in phosphate buffer $(0.1 \mathrm{M}, \mathrm{pH} 7.4)$. The brainstem was cut at $70 \mu \mathrm{m}$, and the extent of the lesion was visualized after processing sections for cytochrome oxidase histochemistry.

Receptive field of $n R T$ cells. In four rats, the receptive field size of single nRT units was assessed before and after SpVi lesion. Glass micropipettes filled with potassium acetate $(0.5 \mathrm{M})$ were used for the recordings. Signals were amplified, bandpass filtered $(150 \mathrm{~Hz}$ to $3 \mathrm{kHz})$, sampled at $20 \mathrm{kHz}$, and stored on hard disks for off-line analysis. The receptive field size of single units was determined by manual whisker deflection under a dissecting microscope. Because in lightly anesthetized rats central neurons respond to several whiskers, it was found impractical to further assess receptive field sizes by means of controlled deflection of individual whiskers. In the context of the present study, the important issue was rather to ascertain whether nRT cells identified as single-whisker responsive by manual deflection indeed responded to a single whisker. This test was performed in a subset of cells by using air jet stimuli to simultaneously deflect a large number of vibrissae. Air jets were generated by a Picospritzer (General Valve, Brooshire, TX) connected to a narrow-bore pipette (tip diameter, $200 \mu \mathrm{m}$ ). The pipette was positioned at distance $(6-8 \mathrm{~cm})$ from the whiskers in front of the animal, and the blast was directed away from the rat's face to avoid as much as possible stimulation of other orofacial sensory afferents. This created a cone-shaped air displacement that deflected approximately six to eight whiskers about the PW. First, the responsive whisker was cut at $2 \mathrm{~cm}$ from the pad, and a peristimulus time histogram (PSTH; bin width, $2 \mathrm{msec}$ ) was built by compiling 20 responses to air jet stimuli (stimulus duration, $50 \mathrm{msec}$; interstimulus interval, $1.5 \mathrm{sec}$ ). Then, the effective whisker was inserted into a $2 \mathrm{~mm}$ glass capillary, and a second PSTH was compiled. The capillary gently pressed against the pad to completely mask the PW. The delay between the command voltage and the actual motion of the vibrissae was measured by placing a piezoelectric film (Measurement Specialties, Fairfield, NJ) at the same distance from the tip of the micropipette. This delay $(\sim 13 \mathrm{msec})$ was subtracted from the recordings to build PSTHs of sensory-evoked responses.

Cross-whisker inhibition. In SpVi lesioned rats, most VPM cells responded to a single whisker. In four animals, however, residual AW ON responses were detected in the recordings, and histological controls revealed that lesions were incomplete. Results from these animals were not considered for analysis. Once a unit was isolated, the micropipette was advanced until spike amplitude reached $8-10 \mathrm{mV}$. From that juxtacellular position, positive DCs (1-4 nA) were applied to induce tonic discharges (15-25 Hz). Spike suppression was assessed during this background activity by deflecting the rostral, caudal, ventral, and dorsal AWs in the direction that best suppressed tonic discharges as determined with a hand-held probe. Whiskers were cut at $10 \mathrm{~cm}$ from the skin, and the tip was inserted into the groove of a beveled straw attached to a ceramic bimorph bender (Physik Instrumente, Karlsruhe, Germany). Each vibrissa was deflected in turn from its resting position using ramp-andhold waveforms (rise/fall times, $15 \mathrm{msec}$; total duration, $200 \mathrm{msec}$; amplitude, 1-2 mm). Depending on the steadiness of background discharges, stimuli were delivered over periods of $2-3 \mathrm{~min}$ at interstimulus interval of $1.2 \mathrm{sec}$. After completion of this stimulation protocol a similar test was performed with one or two non-adjacent whiskers. In additional experiments, we also investigated the direction sensitivity of lateral inhibition by deflecting each AW in four directions spanning $360^{\circ}$ (e.g., in $90^{\circ}$ increments relative to the horizontal alignment of the whisker rows).

Barreloid and cell labeling. Another series of experiments aimed at determining whether the magnitude of lateral inhibition was related to the spread of extrabarreloid dendrites in surrounding barreloids. Rats were first anesthetized with a mixture of ketamine $(75 \mathrm{mg} / \mathrm{kg})$ plus xylazine $(5 \mathrm{mg} / \mathrm{kg})$, and a barrel column in the right hemisphere was located by recording unit responses to manual whisker deflection. Then, a micropipette (tip diameter, $\sim 6 \mu \mathrm{m}$ ) containing Fluoro-Gold (FG; $2 \%$ in 0.1 m cacodylate buffer, $\mathrm{pH}$ 7.0; Fluorochrome, Denver, CO) was lowered in layer 4 (depth, $750 \mu \mathrm{m}$ ) of the identified barrel column. The tracer was ejected with positive current pulses (duration, $2 \mathrm{sec}$ ) of $100 \mathrm{nA}$ for 10 min. After completing this protocol, the skin was sutured, rats were given analgesics (Anafen, $5 \mathrm{mg} / \mathrm{kg}$ ), and they were returned to the animal facilities.

Twenty-four to $48 \mathrm{hr}$ after FG injection, animals were reanesthetized with pentobarbital $(50 \mathrm{mg} / \mathrm{kg})$ and prepared for the recording session as described above. VPM cells were recorded with micropipettes (diameter, $0.5-1 \mu \mathrm{m})$ filled with K-acetate $(0.5 \mathrm{M})$ and Neurobiotin (2\%; Vector Laboratories, Burlingame, CA). When a cell was found in a barreloid surrounding the labeled barreloid, the presence of inhibition was detected by driving the unit with DC, whereas deflecting the vibrissa represented in the labeled barreloid in four orthogonal directions (see above). After completion of the stimulation protocol, neurons were juxtacellularly stained by the application of positive current pulses (2-5 nA, 200 msec duration, $50 \%$ duty cycle) for $5 \mathrm{~min}$ (Pinault, 1996). At the end of the experiments, rats were perfused under deep anesthesia with saline followed by a fixative containing $4 \%$ paraformaldehyde and $0.5 \%$ glutaraldehyde in phosphate buffer $(0.1 \mathrm{M}, \mathrm{pH}$ 7.4). Brains were removed, postfixed overnight in the same fixative, and cut coronally at $70 \mu \mathrm{m}$ with a freezing microtome.

Data analysis-quantification. Data analysis was performed off-line with the Neuroexplorer (Plexon, Dallas, TX) and Excel (Microsoft, Redmond, WA) software. Spike events were compiled into PSTHs of 100 125 responses with $2 \mathrm{msec}$ bin width. Units were considered for analysis only if none of the AWs induced a statistically significant $\mathrm{ON}$ response. This test was performed by comparing firing rates within a $20 \mathrm{msec}$ poststimulus window to that estimated over a $100 \mathrm{msec}$ period before stimulus onset ( $\alpha=0.025$; one-tailed $t$ test). Then we tested for the presence of statistically significant inhibitory responses by comparing firing rates within a $40 \mathrm{msec}$ time window after stimulus onset to prestimulus firing rates estimated over a $100 \mathrm{msec}$ period $(\alpha=0.025$; onetailed $t$ test). To accommodate the latency of feedback inhibition, the start of this window was offset by $6 \mathrm{msec}$ from the start of the stimulus. 
The magnitude of inhibition was rated as the percentage difference in the mean number of counts per bin during the prestimulus and poststimulus time windows. Before comparing the inhibitory impact of each AW, we first ascertained that the magnitude of inhibition did not relate to the level of prestimulus background discharges. Correlation analysis in a population of 107 AWs revealed that, within the range of imposed background discharges $(15-25 \mathrm{~Hz}$ ), magnitude of spike suppression was unrelated to mean prestimulus firing rate $\left(R^{2}=0.07 ; p<\right.$ 0.0001).

Barreloids and neurons were reconstructed from serial sections with the aid of a computer system (Neurolucida, version 5; MicroBrightField, Colchester, VT). Arrays of retrogradely labeled cells were outlined by convex contours that were smoothed and connected to generate a solid picture of the barreloids. Morphometric analysis and three-dimensional reconstructions were made with the NeuroExplorer software equipped with the Solid Rendering module (MicroBrightField). The length and surface area of the dendrites were measured after correction for shrinkage in the $z$-axis. The shrinkage factor was determined by computing the ratio of section thickness used for tissue sectioning to that measured on slides with the $z$-axis of the microscope stage.

Histochemistry and immunohistochemistry. After three washes in PBS (0.01 M, pH 7.4), brain sections were treated for $30 \mathrm{~min}$ with a solution of $50 \%$ ethanol plus $2 \%$ hydrogen peroxide. They were rinsed several times in PBS and preincubated for $1 \mathrm{hr}$ in PBS with 3\% normal goat serum and $0.3 \%$ Triton $\mathrm{X}-100$. Then they were incubated overnight in the same medium containing an anti-Fluoro-Gold antiserum (1:8000; Chemicon, Temecula, CA). The antibody was revealed using a peroxidase-labeled secondary antibody (goat IgG; Chemicon) and 3,3'-diaminobenzidine tetrahydrochloride (DAB) as a substrate (brown reaction product). Next, sections were processed for Neurobiotin histochemistry using the $\mathrm{ABC}$ kit (Vector Laboratories) and nickel-DAB (black reaction product). Finally, sections were mounted on gelatin-coated slides, dehydrated in alcohols, cleared in toluene, and coverslipped without counterstaining. Photomicrographs were taken with a Spot RT camera (Diagnostic Instruments, Sterling Heights, MI) and imported in Photoshop 6.0 (Adobe Systems, San Jose, CA) for contrast and brightness adjustments.

\section{Results}

\section{Validation of the experimental approach}

Wiring diagrams in Figure 1 show different ways lateral inhibition may occur in the barreloids. Considering cell 1 in barreloid D3, if both VPM and nRT cells respond to multiple whiskers, deflection of whisker D2 could inhibit cell 1 through several paths of recurrent connections (Fig. 1A). These include the possibility that cell 1 only responds to whisker D3, but that other cells within barreloid D3 respond to whisker D2 (cell labeled D3-d2). If VPM cells respond to a single whisker and nRT cells to several, then whisker D2 could inhibit cell 1 via two parallel paths (Fig. $1 B$ ). Finally, if both VPM and nRT cells are monowhisker responsive, then whisker D2 could inhibit cell 1 only through synaptic contacts made by D2-responsive nRT cells on the extrabarreloid dendrites of cell 1 (Fig. 1C). Thus, to assess the role of extrabarreloid dendrites as a substrate of lateral inhibition, experimental condi-

A
B

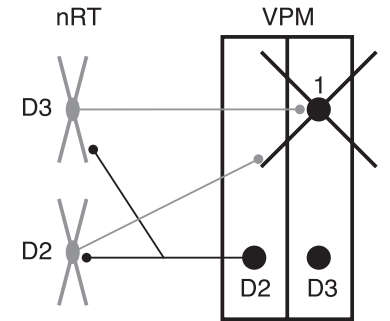

C

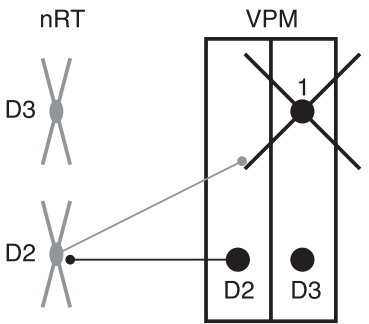

Figure 1. Neuronal circuits that may mediate lateral inhibition in VPM. Wiring diagram $A$ shows different ways cell 1 in barreloid D3 may be inhibited by whisker D2 when both relay and $n R T$ cells respond to multiple whiskers. $B$, Relay cells respond to a single whisker and $n R T$ cells to several. C, Both relay and $n R T$ cells are monowhisker responsive (see Results for full

Figure 2. Reduction of receptive field size in nRT by SpVi lesion. $A, B$, In lightly anesthetized rats, nRT cells respond on average we with air jet stimuli. Population PSTHs (24 cells) in ( show responses of nRT cells to air jet stimuli applied before (white area) and after (gray area) inserting the PW into a glass capillary. Cytochrome oxidase-stained horizontal section in D shows the extent of the lesion (dashed line). Scale bar, $1 \mathrm{~mm}$. 7th, Tract of the facial nucleus.

tions must be such that both VPM and nRT cells respond to a single whisker. Previous studies have shown that in lightly anesthetized animals, receptive fields in VPM were reduced to a single vibrissa after SpVi lesion (Lee et al., 1994a; Friedberg et al., 1999; Timofeeva et al., 2004), but it remained unknown whether such lesion also reduced receptive field sizes in nRT. In a first series of experiments, we investigated that issue.

In our recording conditions, spontaneous activity in nRT was low $(<2 \mathrm{~Hz})$ and consisted of a mixture of single spikes and bursts, which allowed us to clearly identify vibrissa-evoked responses both from the computer display and the sound monitor. In normal rats, $\mathrm{nRT}$ cells responded on average to $2.42 \pm 1.13$ whiskers $(n=57)$, but responsiveness was reduced to $1.03 \pm 0.15$ whisker after SpVi lesion $(n=90)$ (Fig. $2 A, B)$. The reduction of receptive field size was also assessed by air jet stimulation in a subset of cells $(n=24)$. In SpVi lesioned rats, population PSTH (Fig. 2C) to combined deflection of PWs and AWs exhibited a prominent peak at stimulus onset, but responses were completely obliterated after inserting the effective whisker into a glass capillary. Histological controls confirmed that lesions completely destroyed the ventral portion of the SpVi (e.g., the whiskerresponsive region) (Henderson and Jacquin, 1995) and a large part of the trigeminal tract (Fig. 2D). Because SpVi lesion ren- 

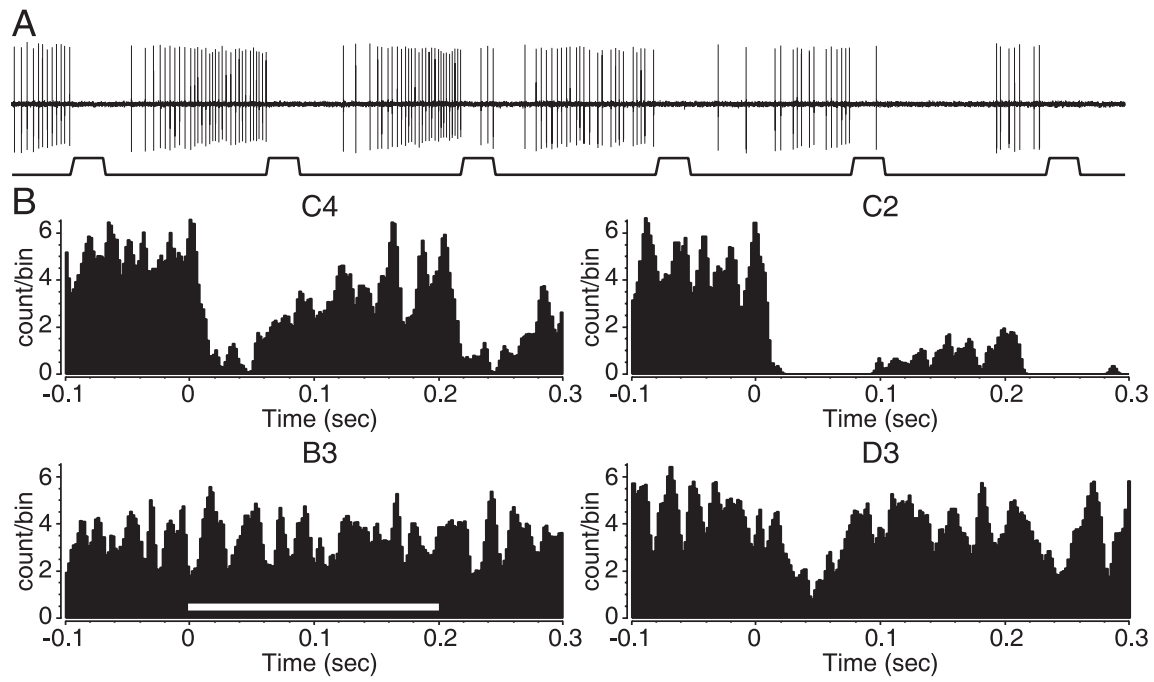

Figure 3. AW-evoked suppression of tonic discharges induced by juxtacellular current application. Traces in $A$ show transient suppression of background discharges in a C3-responsive cell by deflecting whisker C2. PSTHs in $B$ show the magnitude of suppression produced in the same cell by deflecting AWs $C 4, C 2, B 3$, and D3. Whisker deflection occurred at time 0 and lasted for 200 msec (white bar within PSTH under B3 label).

dered both VPM and nRT cells monowhisker responsive, this experimental approach allowed us to investigate the impact of nRT input on extrabarreloid dendrites after deflecting AWs (scenario depicted in Fig. 1C). That being established, the following predictions could be made: (1) because relay cells never extend dendrites beyond a neighboring barreloid (Varga et al., 2002), lateral inhibition should only ensue from deflection of an adjacent vibrissa; (2) because relay cells do not send dendrites into all surrounding barreloids (Varga et al., 2002), lateral inhibition should be asymmetrically distributed; and (3) the magnitude of inhibition produced in a given cell by an AW should be related to the extent to which its dendrites spread in the corresponding adjacent barreloid.

\section{Spatial patterns of lateral inhibition}

We examined the suppressive effect of 118 AWs and 30 non-AWs on the tonic discharges of 31 relay cells. In these cells, spike suppression occurred without excitation

Table 1. Magnitude of AW-evoked inhibition in barreloid cells (percentage suppression with respect to prestimulus level)

\begin{tabular}{|c|c|c|c|c|}
\hline \multirow[b]{2}{*}{ PW } & \multicolumn{4}{|l|}{ AW } \\
\hline & Rostral & Caudal & Dorsal & Ventral \\
\hline B2 & 47.41 & 83.37 & $b$ & $b$ \\
\hline B2 & 14.99 & 84.78 & $b$ & \multirow{2}{*}{$\begin{array}{l}85.34 \\
b\end{array}$} \\
\hline C1 & 54.28 & $a$ & 63.27 & \\
\hline C1 & \multirow{2}{*}{$\begin{array}{l}95.27 \\
b\end{array}$} & $a$ & & $b$ \\
\hline $\mathrm{C} 2$ & & 78.82 & 79.96 & $b$ \\
\hline $\mathrm{C} 2$ & 17.27 & 93.30 & 87.35 & $b$ \\
\hline $\mathrm{C} 2$ & 30.77 & 81.50 & 44.78 & $b$ \\
\hline $\mathrm{C} 2$ & 85.29 & $b$ & $b$ & \multirow{2}{*}{$\begin{array}{l}76.60 \\
b\end{array}$} \\
\hline $\mathrm{C} 2$ & 64.18 & 79.29 & $b$ & \\
\hline $\mathrm{C} 2$ & 73.37 & 66.36 & 73.53 & 28.72 \\
\hline $\mathrm{C} 2$ & \multirow{2}{*}{$\begin{array}{l}68.86 \\
b\end{array}$} & 86.24 & & 93.96 \\
\hline $\mathrm{C} 2$ & & 20.04 & 17.43 & \multirow{2}{*}{$\begin{array}{l}74.88 \\
b\end{array}$} \\
\hline C 3 & 37.40 & 69.30 & $b$ & \\
\hline C 3 & 33.10 & 34.80 & $b$ & 74.60 \\
\hline $\mathrm{C} 3$ & 79.36 & 93.19 & $b$ & 47.73 \\
\hline $\mathrm{C} 3$ & 24.54 & 15.72 & $b$ & 62.77 \\
\hline C4 & 18.00 & 80.06 & $b$ & \multirow{2}{*}{$\begin{array}{l}47.06 \\
b\end{array}$} \\
\hline D2 & 77.11 & 29.78 & 27.82 & \\
\hline D2 & 81.41 & 79.48 & 36.75 & 68.71 \\
\hline D3 & 52.19 & 76.78 & $b$ & 22.98 \\
\hline D3 & 85.49 & 73.23 & $b$ & 29.76 \\
\hline D3 & 61.76 & 79.46 & $b$ & \multirow{2}{*}{$\begin{array}{l}59.26 \\
b\end{array}$} \\
\hline D3 & 82.24 & 31.15 & 30.77 & \\
\hline D3 & 76.69 & 72.88 & 59.23 & \multirow{2}{*}{$\begin{array}{l}29.37 \\
b\end{array}$} \\
\hline D3 & 67.39 & 57.10 & 76.86 & \\
\hline D4 & 74.10 & 87.26 & $b$ & \multirow{2}{*}{$\begin{array}{l}61.39 \\
b\end{array}$} \\
\hline D4 & 86.06 & 90.06 & 30.77 & \\
\hline E1 & 81.70 & 91.80 & 91.82 & $a$ \\
\hline E1 & 70.76 & $b$ & $b$ & $a$ \\
\hline E2 & 67.67 & 68.36 & $b$ & $a$ \\
\hline E3 & $b$ & 75.25 & $b$ & $a$ \\
\hline Mean & 61.02 & 69.82 & 55.25 & 57.54 \\
\hline $\pm S D$ & 23.94 & 22.90 & 25.50 & 22.39 \\
\hline & \multicolumn{2}{|c|}{ Rows: $65.34 \pm 23.64^{c}$} & \multicolumn{2}{|c|}{ Arcs: $56.48 \pm 23.46^{c}$} \\
\hline
\end{tabular}

${ }^{a}$ Untested or untestable.

${ }^{b}$ No significant inhibition.

${ }^{`}$ No significant difference between rows and arcs ( $t$ test; $\left.p=0.11\right)$. with a magnitude that depended on the location of the AW on the pad. Figure 3 shows a representative case of cross-whisker inhibition in which four AWs were deflected in the direction that best inhibited a C3-responsive cell. Whiskers C2 and C4 suppressed discharges by 93 and 79\%, respectively, whisker D3 by $48 \%$, and whisker B3 did not produce any inhibition (Fig. 3B). Table 1 provides a detailed account of the prevalence and magnitude of inhibition for a population of 31 barreloid cells. On average, individual cells were inhibited by $2.68 \pm 0.79 \mathrm{AWs}$, with a clear prevalence for whiskers located within rows. Significant suppression of background discharges was produced by $92 \%$ of AWs within rows $(n=59)$ but only by $48 \%$ of AWs within $\operatorname{arcs}(n=$ 58). Among the effective whiskers, however, no significant difference was found between the magnitude of inhibition evoked by AWs within rows or arcs, $(65.34 \pm 23.64$ and $56.48 \pm 23.46 \%$, respectively; $t$ test; $p=0.11$ ). Spike suppression was never observed after deflection of non-AWs.

In six cells, we also examined whether the magnitude of inhibition depended on the direction of AW displacements (Fig. 4). Among the 24 AWs tested, 12 produced no inhibition or remained equally effective $( \pm 10 \%)$ whatever the direction of motion, whereas the amount of spike suppression produced by the other whiskers demonstrated clear direction sensitivity.

\section{Lateral inhibition and dendroarchitecture}

To obtain direct evidence for the role of extrabarreloid dendrites in cross-whisker inhibition, single barreloids were outlined by retrograde labeling, and individual cells within adjacent barreloids were stained with Neurobiotin. We examined whether the magnitude of inhibition produced in those cells by deflecting the vibrissa represented in the backfilled barreloid related to the spread of their dendrites within that same barreloid. The magnitude of inhibition was rated according to the direction of deflection that best suppressed spike discharges. Figure 5 shows a representative case of double labeling that combines the backfilling of barreloid D3 with the juxtacellular staining of two cells in barreloids D2 and D4. Note that the cell in barreloid D4 sent dendrites into barreloid D3 and was inhibited by whisker D3 (Fig. 5C), whereas the D2-responsive cell did not 

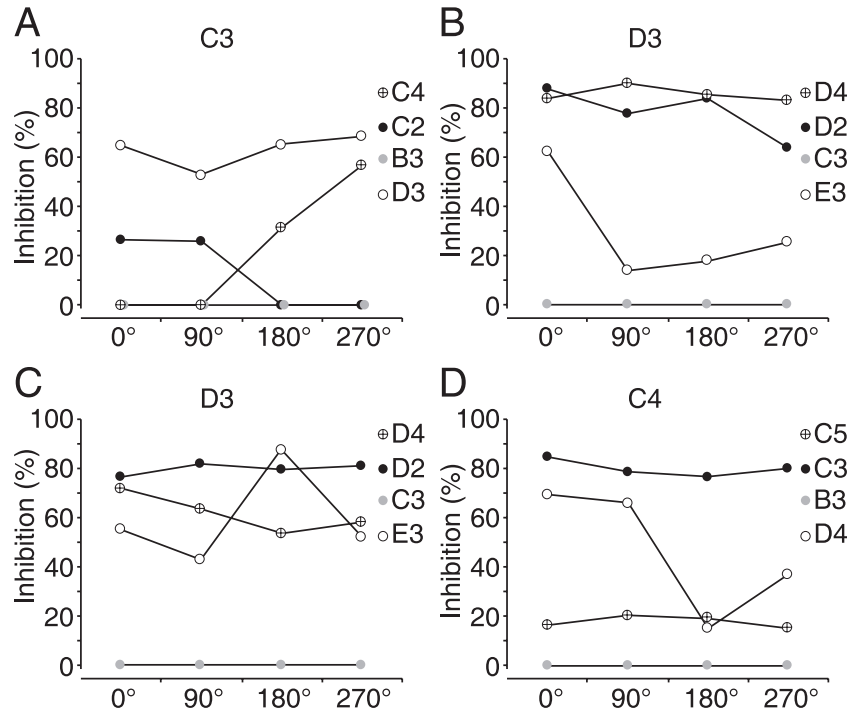

Figure 4. Direction sensitivity of lateral inhibition in barreloids. $A-D$, Graphs show the magnitude of spike suppression produced in four cells by deflecting each AW in four directions $\left(0^{\circ}\right.$, rostralward; $90^{\circ}$, dorsalward, and so on). For each cell, PWs and AWs are identified above and on the right-hand side of the graphs, respectively.

send any dendrite into barreloid D3 and was not inhibited by whisker D3 (Fig. 5D). Among the 17 cells tested and recovered after staining, five did not demonstrate inhibition, and none of the latter sent dendrites into the backfilled barreloid. Lateral inhibition was present in the other cells with a magnitude that strongly correlated with the extent to which dendrites invaded the backfilled barreloid (Fig. 6A). As the length of dendrites increases, inhibition increases steeply to reach $90 \%$ spike suppression at a cumulated length of $\sim 1$ $\mathrm{mm}$. This figure is actually close to the maximum degree of spike suppression observed after PW deflection (e.g., 92\% using the same poststimulus time windowing; $n=4$ cells; data not shown). Thus, within the range of background discharges used to test inhibition $(15-25 \mathrm{~Hz})$, data points are best fitted by linear regression with $R^{2}=$ $0.86(p<0.0001)$. Because distal dendrites exhibit little tapering (Ohara and Havton, 1994; Varga et al., 2002), using dendritic surface areas instead of dendritic lengths did not significantly alter the linear relationship.

An almost perfect correlation was found between the magnitude of inhibition and proximity of cell bodies to the labeled barreloid $\left(R^{2}=0.97 ; p<0.0001\right)$ (Fig. $\left.6 B\right)$. As distance decreases, the magnitude of inhibition increases linearly up to $90 \%$ spike suppression for cells located next to the margin of the labeled barreloid. Accordingly, the cumulated length of labeled dendrites in the backfilled barreloid also closely related to the distance between cell bodies and the border of that barreloid. The graph in Figure $6 C$ shows that data points are best fitted by a logarithmic function $\left(R^{2}=0.82 ; p<0.0001\right)$. We then examined whether a logarithmic increase in dendritic length also characterizes dendritic arbors that remain confined within the home barreloid of the cell. The intrabarreloid dendritic arborization of four cells was sliced at $10 \mu \mathrm{m}$ intervals, and we computed the cumulated length of dendrites past each cut (Fig. 6D). After normalization, the average increase in length also followed a logarithmic function $\left(R^{2}=0.98 ; p<0.0001\right)$. Thus, whether dendrites remain confined within a barreloid or traverse septa, they exhibit a similar logarithmic increase in dendritic length. This suggests that the position of a cell within a barreloid is the main determinant of the amount of dendrites sent into an adjacent barreloid.

\section{Discussion}

Morphometric analysis of VPM neurons in rodents have disclosed a single class of relay cells with a stereotyped bushy dendroarchitecture (Harris, 1986; Chiaia et al., 1991; Ohara and Havton, 1991; Varga et al., 2002). When examined in relation with the three-dimensional structure of the barreloids, however, it was found that VPM cells differed from one another by the spatial distribution of their dendrites in surrounding barreloids (Varga et al., 2002). In the present study, we report that this anatomic feature determines whisker-specific patterns of lateral inhibition. The efficacy of inhibition increases with the amount of dendritic spread in a given adjacent barreloid, which in turn depends on the distance that separates cell bodies from the border of that barreloid.

\section{Spatial asymmetry of lateral inhibition}

In cytochrome oxidase-stained coronal sections of the thalamus, barreloids appear as darkly reactive, curved, tapering rods that extend through the thickness of VPM. In sections cut normal to their long axis, barreloids appear as an array of rectangular blobs with center-to-center spacing of $\sim 100 \mu \mathrm{m}$ along rows and of $\sim 200 \mu \mathrm{m}$ along arcs of whisker representation (Land et al., 1995; Haidarliu and Ahissar, 2001). Given that the dendritic field span of relay cells does not exceed $250 \mu \mathrm{m}$ (Chiaia et al., 1991; Ohara and Havton, 1991; Varga et al., 2002), the geometry of the barreloids thus limits the spread of dendrites to a single adjacent barreloid along an arc of whisker representation. These geometric constraints likely explain why most cells failed to demonstrate lateral inhibition after deflection of either the dorsal or ventral AW and also why, in previous studies, maximal inhibitory interactions in VPM were observed primarily with whisker row stimuli (Ghazanfar and Nicolelis, 1997; Brecht and Sakmann, 2002). Only in the ventral part of VPM, where barreloids taper, could dendrites spread in most of the adjacent barreloids and inhibition be possibly elicited by both AWs within an arc. This could explain why $\sim 13 \%$ of the cells we recorded (Table 1 ) were suppressed by two adjacent whiskers along an arc.

\section{Dendroarchitecture and receptive field structure}

Our results show that the spatial distribution of extrabarreloid dendrites closely relates to the distance that separates cell bodies from the border of surrounding barreloids. The shorter that distance, the larger the amount of dendrites sent into the nearest barreloids. Because both cell body location and patterns of lemniscal inputs are likely determined by genetic factors, one may wonder whether the distribution of extrabarreloid dendrites replicates the structure of surround receptive fields. In other words, do relay cells send dendrites in all barreloids representing whiskers that compose their receptive field? Although this possibility appears congruent with most estimates of receptive field size in VPM (three to six whiskers) (Simons and Carvell, 1989; Armstrong-James and Callahan, 1991; Chiaia et al., 1991; Diamond et al., 1992; Friedberg et al., 1999; Minnery et al., 2003), it faces the difficulty that surround receptive fields may include whiskers that are not immediately adjacent to the PW, whereas relay cells never extend dendrites farther than one surrounding barreloid (Nicolelis and Chapin, 1994; Brecht and Sakmann, 2002). In contrast, one can argue that a match might be found if more stringent thresholding and time windowing criteria were used to define receptive field sizes. There is now clear evidence that multiwhisker receptive field synthesis occurs in the principalis nucleus (PrV) through inter-subnuclear trigeminal projec- 

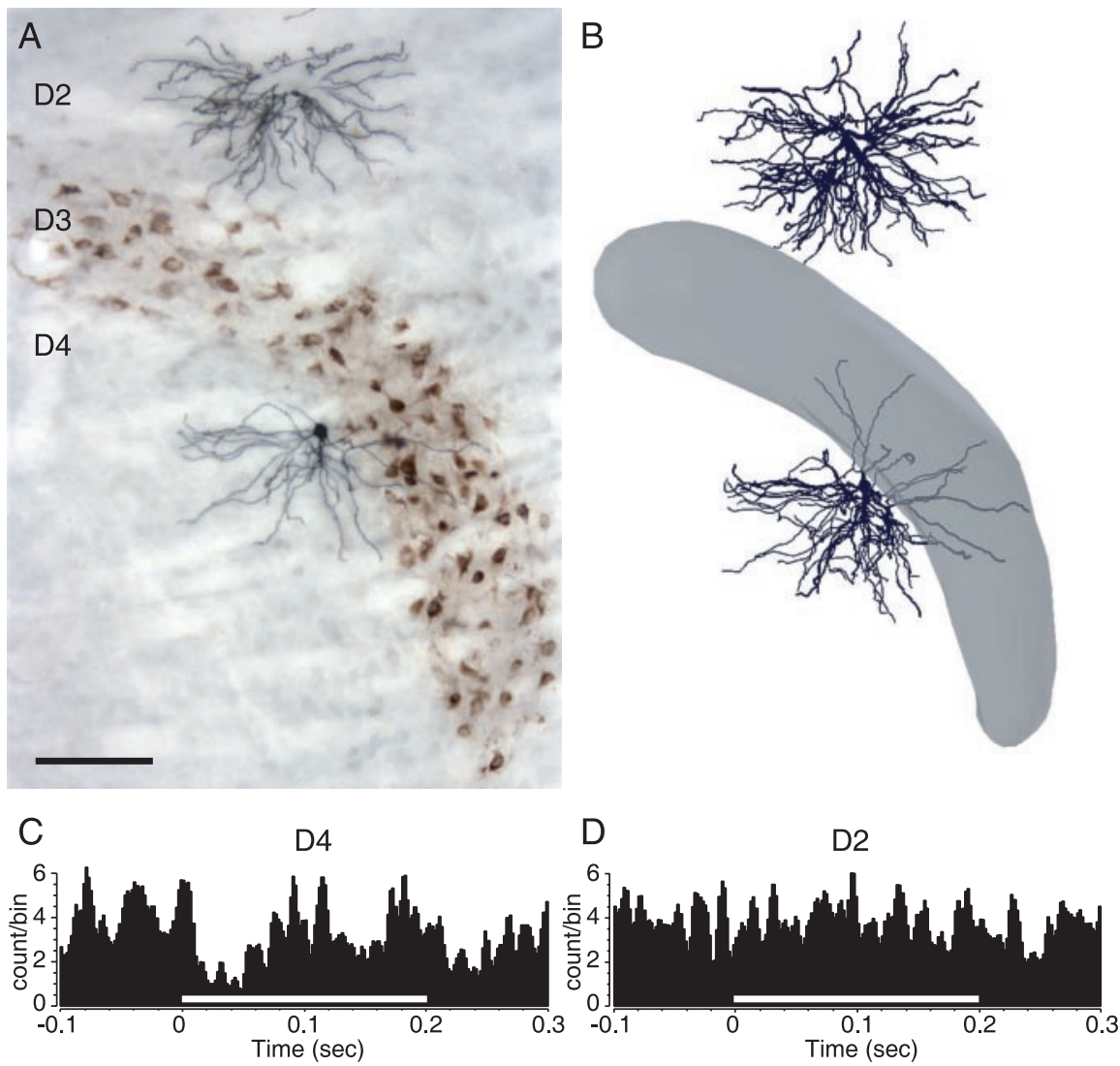

Figure 5. Relationship between dendroarchitecture and lateral inhibition in the barreloids. $A$, In the histological material, barreloid D3 was backfilled by Fluoro-Gold injection in barrel D3, and two cells located in barreloids D2 and D4, respectively, were labeled juxtacellularly after assessing the magnitude of spike suppression produced by whisker D3 deflection. Barreloid and cell reconstructions are shown in $B$. The D4-responsive cell sent dendrites within barreloid D3 and was inhibited by whisker D3 (PSTH in $C$, whereas the D2-responsive cell did not send any dendrite within barreloid D3 and was not inhibited (PSTH in D). Scale bar, (in A) $100 \mu \mathrm{m}$.

tions (Timofeeva et al., 2004). The most direct route for AW inputs to reach VPM involves monosynaptic projections from the interpolaris or caudalis nuclei to $\mathrm{PrV}$, but additional polysynaptic routes are possible. These include, for example, projections from caudalis to SpVi and then to PrV (Jacquin et al., 1990) or more complex synaptic interactions in the spinal complex that may contribute to enlarge receptive field. Thus, depending on the poststimulus time window used to analyze PSTHs, receptive fields may shrink or enlarge to include up to 15 whiskers under light anesthesia (Nicolelis and Chapin, 1994). For the moment, the spatial organization of vibrissal receptive fields has received little attention (but see Brecht and Sakmann, 2002); however, if one assumes that dendrites are not randomly distributed among barreloids, their distribution should relate to some aspect of receptive field organization, or again to response properties to coordinated deflection of a small group of vibrissae.

\section{Impact of AW-evoked remote inhibition}

By using an experimental approach that rendered thalamic cells monowhisker responsive, we examined the extent to which VPM neurons manifest an exclusively inhibitory component to their surround receptive fields. We found that lateral inhibition was solely present in cells that sent dendrites into the barreloid representing the stimulated whisker. This result dismisses the possibility that background discharges induced in a VPM neuron and subthreshold input from an adjacent barreloid summate to de- polarize nRT cells and inhibit barreloid cells in a recurrent manner. In that case, cross-whisker inhibition should be unrelated to the distribution of dendrites in surrounding barreloids, and the five cells that did not send dendrites into the backfilled barreloid should have been inhibited as well.

Patch-clamp recordings have shown that AW deflection induces large amplitude inhibitory postsynaptic potentials in VPM cells (Brecht and Sakmann, 2002), but conditions under which experiments were performed do not permit identification of the respective contribution of recurrent and lateral inhibitory circuits in cell inhibition. In contrast, modeling studies in which the entire morphology of the neuron was taken into account have shown that the bushy dendroarchitecture of VPM cells creates several independent domains of synaptic operations (Neubig and Destexhe, 2001). For inhibitory synapses at all dendritic locations, significant electrotonic filtering occurs, but $>79 \%$ of the charge transfer reaches the soma where it disperses into other dendritic trees to return to the extracellular space. Thus, inhibitory synapses, albeit confined to one or few dendritic trees, could still exert a significant depressive effect, especially when cells are maintained in a state of high somatic conductance by current injection.

Although previous studies argue against a prominent role for lateral inhibition in the subcortical processing of spatial information (Simons and Carvell, 1989; Minnery et al., 2003), our results show that nRT inputs on extrabarreloid dendrites can significantly depress relay cell excitability. The extent to which this particular mode of lateral inhibition contributes to spike suppression in cells that normally respond to multiple whiskers remains to be assessed. Previous studies have shown that AW responses in VPM lag PW responses by 3-5 msec, and that nRT inhibition begins 2-5 msec after the onset of PW responses (Shosaku, 1985, 1986; Armstrong-James and Callahan, 1991; Diamond et al., 1992; Lee et al., 1994a; Friedberg et al., 1999; Hartings et al., 2000; Minnery et al., 2003). If one assumes that prethalamic cells that are best tuned to the velocity and direction of whisker motion fire first, their thalamic targets will also be the first to reach threshold before significant inhibition occurs. Thus, inhibition operating distally on dendrites could act as a spatial filter that primarily suppresses AW inputs and so contributes to enhance edge detection. A latency-dependent gating mechanism could explain why lateral inhibition is less effective in suppressing PW responses in the thalamus (Simons and Carvell, 1989) and also why nRT lesion or the application of GABA receptor antagonists produce an enlargement of receptive field size in VPM (Lee et al., 1994a,b). This model would also be consistent with a number of recent studies in which it was reported that recruitment order coding provides a powerful, quick, and reliable ensemble code to carry information about sensory stimuli (Panzeri et al., 2001; Petersen et al., 2001; Delorme, 2003; Johansson and Birznieks, 2004). 


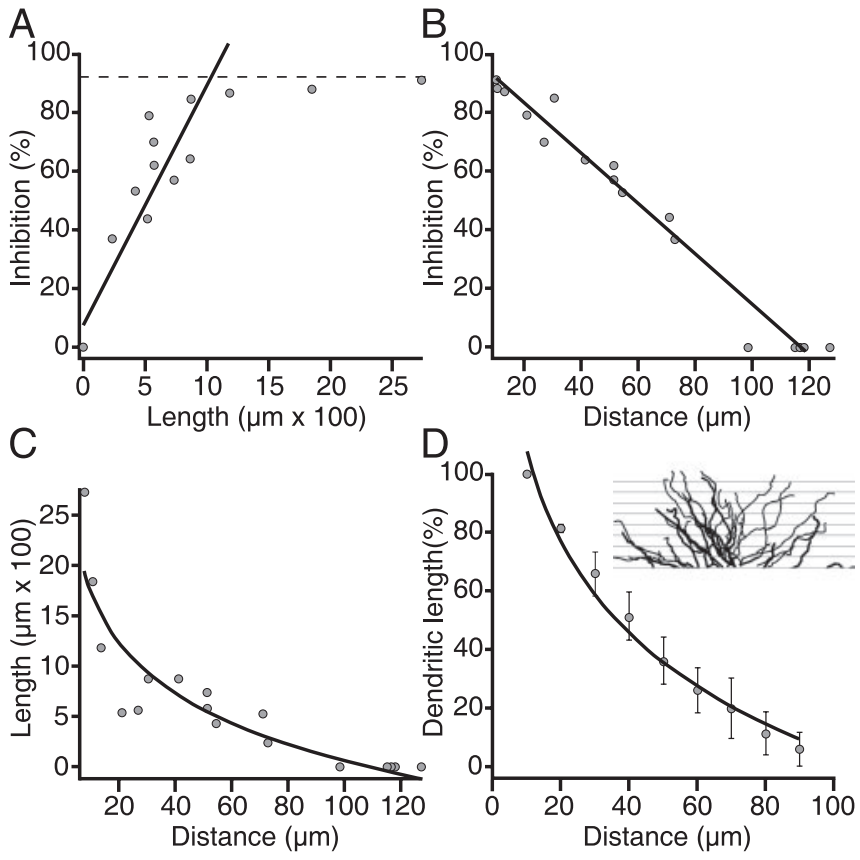

Figure 6. Quantitative relationship between the magnitude of lateral inhibition and anatomical features of barreloid cells. $A$, Graph shows how the magnitude of AW-evoked inhibition relates to the total length of dendritic segments in the corresponding barreloid. Data points were best fitted by linear regression $\left(y=7.10+0.08 \cdot x ; R^{2}=0.86 ; p<0.0001\right)$. Note that data point at 0,0 represents five cells. The dashed line indicates the average degree of inhibition produced by PW deflection (e.g., 92\%). B, Graph shows that the magnitude of inhibition produced by an AW is linearly related to the distance that separates cell bodies from the border of the corresponding barreloid; regression line: $y=98.95-0.84 \cdot x ; R^{2}=0.97 ; p<0.0001 . C$, Graph shows how the length of extrabarreloid dendrites in an adjacent barreloid decreases with distance that separates cell bodies from the border of that barreloid [regression curve: $y=$ $\left.3451.21-738.04 \cdot \ln (x) ; R^{2}=0.82 ; p<0.0001\right]$. D, Plot shows how the cumulated length of dendritic segments inside the barreloid decreases with distance from the cell body $[y=211-$ $\left.44.88 \cdot \ln (x) ; R^{2}=0.98 ; p<0.0001\right]$. Each point represents the average (mean $\pm S D$ ) of normalized values for four dendritic arbors. Insert shows the slicing procedure (10 $\mu \mathrm{m}$ intervals) used to compute dendritic lengths.

\section{Other thalamocortical systems}

Given the highly segregated organization of the vibrissa system, one may wonder whether present results can be considered as a model for synaptic operations in other thalamic nuclei in rat or in other species. As in the VPM of rodents, the terminal fields of $\mathrm{nRT}$ axons in the lateral geniculate nucleus in rats and cats form bands or columns of terminations (Uhlrich et al., 1991; Pinault et al., 1995). In cats, Uhlrich et al. (1991) showed that nRT axons generally distribute to geniculate laminas receiving from left or right eye in accordance with the dominant ocular input to the reticular cell, and that the column of relay cells innervated corresponds approximately to the position of the receptive field of that nRT cell. Given that relay cells in first-order visual and somatosensory thalamic nuclei have similar bushy dendroarchitecture (Sherman and Guillery, 2001), these observations suggest that geniculate cells located next to an nRT projection column should be subjected to lateral inhibition on their distal dendrites. However, considering the overlap of visual receptive fields and the presence of local circuit cells in the lateral geniculate nucleus, clear evidence for this proposal should be difficult to obtain.

\section{References}

Armstrong-James M, Callahan CA (1991) Thalamo-cortical processing of vibrissal information in the rat. II. Spatiotemporal convergence in the thalamic ventroposterior medial nucleus (VPm) and its relevance to gen- eration of receptive fields of S1 cortical barrel neurones. J Comp Neurol 303:211-224.

Barbaresi P, Spreafico R, Frassoni C, Rustioni A (1986) GABAergic neurons are present in the dorsal column nuclei but not in the ventroposterior complex of rats. Brain Res 382:305-326.

Brecht M, Sakmann B (2002) Whisker maps of neuronal subclasses of the rat ventral posterior medial thalamus, identified by whole-cell voltage recording and morphological reconstruction. J Physiol (Lond) 538:495-515.

Brumberg JC, Pinto D, Simons DJ (1996) Spatial gradients and inhibitory summation in the rat whisker barrel system. J Neurophysiol 76:130-140.

Bruno RM, Simons DJ (2002) Feedforward mechanisms of excitatory and inhibitory cortical receptive fields. J Neurosci 22:10966-10975.

Chiaia NL, Rhoades RW, Fish SE, Killackey HP (1991) Thalamic processing of vibrissal information in the rat. II. Morphological and functional properties of medial ventral posterior nucleus and posterior nucleus neurons. J Comp Neurol 314:217-236.

Delorme A (2003) Early cortical orientation selectivity: how fast inhibition decodes the order of spike latencies. J Comp Neurosci 15:357-365.

Désîlets-Roy B, Varga C, Lavallée P, Deschênes M (2002) Substrate for cross-talk inhibition between thalamic barreloids. J Neurosci 22:RC218 (1-4).

Diamond ME, Armstrong-James M, Ebner FF (1992) Somatic sensory responses in the rostral sector of the posterior group (POm) and in the ventral posterior medial nucleus (VPM) of the rat thalamus. J Comp Neurol 318:462-476.

Friedberg MH, Lee SM, Ebner FF (1999) Modulation of receptive field properties of thalamic somatosensory neurons by the depth of anesthesia. J Neurophysiol 81:2243-2252.

Ghazanfar AA, Nicolelis MA (1997) Nonlinear processing of tactile information in the thalamocortical loop. J Neurophysiol 78:506-510.

Goldreich D, Peterson BE, Merzenich MM (1998) Optical imaging and electrophysiology of rat barrel cortex. II. Responses to paired-vibrissa deflections. Cereb Cortex 8:184-192.

Haidarliu S, Ahissar E (2001) Size gradients of barreloids in the rat thalamus. J Comp Neurol 429:372-387.

Harris RM (1986) Morphology of physiologically identified thalamocortical relay neurons in the rat ventrobasal thalamus. J Comp Neurol 251:491-505.

Harris RM (1987) Axon collaterals in the thalamic reticular nucleus from thalamocortical neurons of the rat ventrobasal thalamus. J Comp Neurol 258:397-406

Hartings JA, Temereanca S, Simons DJ (2000) High responsiveness and direction sensitivity of neurons in the rat thalamic reticular nucleus to vibrissa deflections. J Neurophysiol 83:2791-2801.

Hartline HK (1942) The neural mechanism of vision. The Harvey Lectures, Ser 37.

Henderson TA, Jacquin MF (1995) What makes subcortical barrels? In: Cerebral cortex, the barrel cortex of rodents, Vol 12 (Jones EG, Diamond IT, eds), pp 123-187. New York: Plenum.

Jacquin MF, Chiaia NL, Haring JH, Rhoades RW (1990) Intersubnuclear connections within the rat trigeminal brainstem complex. Somatosens Mot Res 7:399-420.

Johansson RS, Birznieks I (2004) First spikes in ensembles of human tactile afferents code complex spatial fingertip events. Nat Neurosci 7:170-177.

Kuffler SK (1953) Discharge patterns and functional organization of mammalian retina. J Neurophysiol 16:37-68.

Land PW, Buffer SA, Yaskosky JD (1995) Barreloids in adult rat thalamus: three-dimensional architecture and relationship to somatosensory cortical barrels. J Comp Neurol 355:573-588.

Lee SM, Friedberg MH, Ebner FF (1994a) The role of GABA-mediated inhibition in the rat ventral posterior medial thalamus. I. Assessment of receptive field changes following thalamic reticular nucleus lesions. J Neurophysiol 71:1702-1715.

Lee SM, Friedberg MH, Ebner FF (1994b) The role of GABA-mediated inhibition in the rat ventral posterior medial thalamus. II. Differential effects of GABAA and GABAB receptor antagonists on responses of VPM neurons. J Neurophysiol 71:1716-1726.

Minnery BS, Simons DJ (2003) Response properties of whisker-associated trigeminothalamic neurons in rat nucleus principalis. J Neurophysiol $89: 40-56$

Minnery BS, Bruno RM, Simons DJ (2003) Response transformation and 
receptive field synthesis in the lemniscal trigeminothalamic circuit. J Neurophysiol 89:40-56.

Neubig M, Destexhe A (2001) Dendritic organization in thalamocortical neurons and state-dependent functions of inhibitory synaptic inputs. Thalamus Relat Syst 1:39-52.

Nicolelis MAL, Chapin JK (1994) Spatiotemporal structure of somatosensory responses of many-neuron ensembles in the rat ventral posterior medial nucleus of the thalamus. J Neurosci 14:3511-3532.

Ohara PT, Havton LA (1994) Dendritic architecture of rat somatosensory thalamocortical projection neurons. J Comp Neurol 341:159-171.

Panzeri S, Petersen RS, Schultz SR, Lebedev M, Diamond ME (2001) The role of spike timing in the coding of stimulus location in rat somatosensory cortex. Neuron 29:769-777.

Paxinos G, Watson C (1986) The rat brain in stereotaxic coordinates. San Diego: Academic.

Petersen RS, Panzeri S, Diamond ME (2001) Population coding of stimulus location in rat somatosensory cortex. Neuron 32:503-514.

Pinault D (1996) A novel single-cell staining procedure performed in vivo under electrophysiological control: morpho-functional features of juxtacellularly labeled thalamic cells and other central neurons with biocytin or Neurobiotin. J Neurosci Methods 65:113-136.

Pinault D, Deschênes M (1998) Anatomical evidence for a mechanism of lateral inhibition in the rat thalamus. Eur J Neurosci 10:3462-3469.

Pinault D, Bourassa J, Deschênes M (1995) Thalamic reticular input to the rat visual thalamus: a single fiber study using biocytin as an anterograde tracer. Brain Res 670:147-152.

Pollak GD, Burger RM, Park TJ, Klug A, Bauer EE (2002) Roles of inhibition for transforming binaural properties in the brainstem auditory system. Hear Res 168:60-78.

Sherman MS, Guillery RW (2001) Exploring the thalamus. San Diego: Academic.

Shosaku A (1985) A comparison of receptive field properties of vibrissa neurons between the rat thalamic reticular and ventro-basal nuclei. Brain Res 347:36-40.

Shosaku A (1986) Cross-correlation analysis of a recurrent inhibitory circuit in the rat thalamus. J Neurophysiol 55:1030-1043.

Simons DJ, Carvell GE (1989) Thalamocortical response transformation in the rat vibrissa/barrel system. J Neurophysiol 61:311-330.

Timofeeva E, Lavallée P, Arsenault D, Deschênes M (2004) The synthesis of multi-whisker receptive fields in subcortical stations of the vibrissa system. J Neurophysiol 91:1510-1515.

Uhlrich DJ, Cucchiaro JB, Humphrey AL, Sherman SM (1991) Morphology and axonal projection patterns of individual neurons in the cat perigeniculate nucleus. J Neurophysiol 65:1528-1541.

Varga C, Sik A, Lavallée P, Deschênes M (2002) Dendroarchitecture of relay cells in thalamic barreloids: a substrate for cross-whisker modulation. J Neurosci 22:6186-6194.

von Bekesy G (1967) Sensory inhibition. Princeton, NJ: Princeton UP.

Welker E, Armstrong-James M, Van der Loos H, Kraftsik R (1993) The mode of activation of a barrel column: response properties of single units in the somatosensory cortex of the mouse after whisker deflection. Eur J Neurosci 5:691-712.

Yokoi M, Mori K, Nakasishi S (1995) Refinement of odor molecule tuning by dendrodendritic synaptic inhibition in the olfactory bulb. Proc Natl Acad Sci USA 92:3371-3375. 